\title{
Minimal to No Bolus Clearance
}

National Cancer Institute

\section{Source}

National Cancer Institute. Minimal to No Bolus Clearance. NCI Thesaurus. Code C127213.

A finding of minimal to no clearance of bolus after swallowing. 